\title{
Kinetics of Polymerization of Vinyl Monomers Initiated by Manganese(III) Acetate. II.
}

\author{
Kesavan Kaliyamurthy, Piramiah Elayaperumal, \\ Thayikkannu BALAKRISHNAN, \\ and Muchi SANTAPPA \\ Department of Physical Chemistry, University of Madras, \\ A.C. College of Technology Campus, Madras-600 025, India.
}

(Received June 12, 1981)

\begin{abstract}
The kinetics of the thermal polymerization of methyl acrylate (MA) and acrylamide (AAM) initiated by manganic ion in aqueous sulfuric acid medium has been studied. The rate of disappearance of [monomer] $\left(R_{\mathrm{p}}\right)$ was found to bear a square dependence on monomer and to be independent of $\left[\mathrm{Mn}^{2+}\right]$ in the case of both the systems. $R_{\mathrm{p}}$ for acrylamide increased with the increase in $\left[\mathrm{H}^{+}\right]$but that for methyl acrylate remained almost constant. The degree of polymerization of the polymers $\left(\bar{X}_{n}\right)$ determined viscometrically was directly proportional to the [monomer] and inversely proportional to $\left[\mathrm{Mn}^{3+}\right]$, for both systems. $\bar{X}_{n}$ increased with an increase in $\left[\mathrm{H}^{+}\right]$in the case of acrylamide and decreased in the case of methyl acrylate. Suitable reaction schemes to explain these experimentally observed facts have been proposed. Kinetic and thermodynamic parameters are also evaluated.

KEY WORDS Kinetics / Polymerization / Acrylamide / Methyl Acrylate / Manganic Ion / Reaction Scheme / Degree of Polymerization /
\end{abstract}

The oxidation kinetics of inorganic and organic substrates by $\left[\mathrm{Mn}^{3+}\right]$ has already been reported. ${ }^{1-3}$ Literature survey revealed that chelate complexes of $\mathrm{Mn}(\mathrm{III})$ initiate the polymerization of vinyl monomers via free radical mechanism in non-aqueous media. ${ }^{4}$ Redox systems containing $\mathrm{Mn}^{3+}$ and an organic substrate like $\mathrm{Mn}^{3+}+$ malonic acid, ${ }^{5}$ $\mathrm{Mn}^{3+}+$ pinacol $^{6}$ and $\mathrm{Mn}^{3+}+$ cyclohexanone ${ }^{7}$ have been found to initiate vinyl polymerization. Santappa et al. ${ }^{8}$ studied the polymerization of acrylamide, acrylic acid, and acrylonitrile in the temperature range from $20-45^{\circ} \mathrm{C}$ using $\mathrm{Mn}^{3+}+$ diglycolic acid and $\mathrm{Mn}^{3+}+$ isobutyric acid redox systems. At elevated temperatures $40-45^{\circ} \mathrm{C}$ they observed the initiation of polymerization both by $\mathrm{Mn}^{3+}$ and primary radicals produced by redox reactions. The literature indicates no reference regarding initiation by only $\mathrm{Mn}^{3+}$ salts in an aqueous medium. It was therefore proposed to establish by the present investigation that vinyl polymerization could be initiated by $\mathrm{Mn}^{3+}$ without any reducing agents. In Part $\mathrm{I}^{9}$ we report the kinetics of polymerization of acrylic acid, methacrylic acid, acrylonitrile and methacrylamide initiated by $\mathrm{Mn}^{3+}$.

\section{EXPERIMENTAL}

\section{Materials}

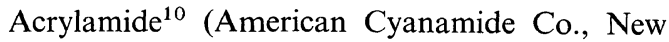
York) was recrystallized twice from warm chloroform. The resulting product was a crystalline white solid; $\mathrm{mp}, 84.5^{\circ} \mathrm{C}$. Methyl acrylate was purified $^{11}$ by washing with $5 \%$ aqueous sodium hydroxide to remove the inhibitor and then washed with water. It was then dried over anhydrous sodium sulphate and distilled twice at reduced pressure in an atmosphere of nitrogen. The distilled product was stored in a refrigerator at about $5^{\circ} \mathrm{C}$. All experiments were conducted in an aqueous sulphuric acid medium. Solutions of sulphuric acid were prepared by suitable dilutions of concentrated acid (A.R., B.D.H.) with double-distilled water and standardized against sodium hydroxide solution. Organic solvents such as chloroform, methyl ethyl ketone, etc., were distilled immediately before use and the middle cuts of the distillates were used. 


\section{K. Kaliyamurthy et al.}

Sodium hydrogen sulphate (E. Merck, Germany) was used to maintain the ionic strength. Manganese(II) acetate (L.R., B.D.H.) was used to prepare manganese(III) acetate by a known method. ${ }^{12}$ The reaction vessel was a pyrex glass tube fitted with a B-24 quickfit socket. A B-24 cone provided with an inlet and outlet tube for nitrogen was fitted into the tube. The reaction mixture containing appropriate quantities of inhibitor free monomer, sulphuric acid, and sodium bisulphate solution was thermostated and deaerated for $30 \mathrm{~min}$. Another reaction vessel containing a blank solution of the same concentraion of monomer as the reaction mixture was interposed between the nitrogen train and the reaction tube to minimize the loss of monomer during deaeration by passing pure dry nitrogen. At the end of the deaeration a $\mathrm{Mn}^{3+}$ solution was added to the reaction mixture and shaken well. The inlet and outlet were then closed by rubber gaskets to maintain the nitrogen atmosphere. After $30 \mathrm{~min}$ the reaction was arrested by cooling the reaction tube in freezing mixture and blowing air slightly through the solution. A known volume of the reaction mixture was added to $25 \mathrm{ml}$ of a bromide-bromate solution. The $10 \mathrm{ml}$ of $5 \mathrm{M}$ sulphuric acid were added and the flask was tightly stoppered and kept in the dark for about 15 minutes. It was mixed with an excess of potassium iodide solution and the liberated iodine was titrated with $0.1 \mathrm{M}$ sodium thiosulphate solution. The same volume of solution from the blank vessel was also titrated and from the differences in titre values, $R_{\mathrm{p}}$ was computed. $10 \mathrm{ml}$ of the reaction mixture were introduced into another conical flask and mixed with $2 \%$ potassium iodide solution and the liberated iodine was titrated with $0.0025 \mathrm{M}$ sodium thiosulphate. A blank titration was also done and the rate of disappearance of $\mathrm{Mn}^{3+}\left(-R_{\mathrm{m}}\right)$ was calculated from these titre values. The degree of polymerization was determined viscometrically using appropriate Mark-Houwink relationships. For poly(acrylamide) ${ }^{13}[\eta]=6.8 \times 10^{-4}\left(M_{v}\right)^{0.66}$ in water at $30^{\circ} \mathrm{C}$. For poly(methyl acrylate $)^{14}[\eta]=0.397 \times$ $10^{-4}\left(M_{v}\right)^{0.772}$ in butanone at $30^{\circ} \mathrm{C}$. The viscosity measurements were made with a Ubbelohde suspended level dilution viscometer (fitted with sinter) in a thermostat with a temperature contol of $\pm 0.01^{\circ} \mathrm{C}$.

\section{Preliminary Experiments}

Before discussing the experimental results, a brief analysis of the preliminary experiments will now be made: (i) under our reaction conditions, no photochemical initiation of acrylamide or methyl acrylate was noticed. On the other hand, thermal polymerization could be easily initiated by $\mathrm{Mn}^{3+}$; (ii) no induction period was observed under deaerated conditions. Polymerization was found to be inhibited by the presence of air or oxygen or hydroquinone. This indicates that the reaction is free radical in nature. (iii) a steady-state rate was reached within 20 minutes in both cases; (iv) $\left[\mathrm{Mn}^{2+}\right]$ was about 20 times higher than $\left[\mathrm{Mn}^{3+}\right]$ in order to prevent the following disproportionation reaction:

$$
2 \mathrm{Mn}^{3+} \rightleftharpoons \mathrm{Mn}^{2+}+\mathrm{Mn}^{4+}
$$

An increase in $\left[\mathrm{Mn}^{2+}\right]$ above this ratio caused no change in the rates and (v) the oxidation of water by $\mathrm{Mn}^{3+}$ under our experimental conditions was negligible.

\section{RESULTS AND DISCUSSION}

\section{(A) $\mathrm{Mn}^{3+}+$ Acrylamide + Aqeuous Sulphuric Acid System}

Rate of Disappearance of Monomer, $R_{\mathrm{p}}$

The concentration of monomer was varied from $0.3858 \mathrm{M}$ to $0.7717 \mathrm{M}$. $R_{\mathrm{p}}$ had square dependence on the [monomer]. The $\log R_{\mathrm{p}} v s . \log$ [M] plot gave a slope of two and the plot of $R_{\mathrm{p}}$ against $[\mathrm{M}]^{2}$ was linear with zero intercept indicating that the order with respect to monomer was two (Figure 1A). The concentration of $\mathrm{Mn}^{3+}$ was varied from $0.001875 \mathrm{M}$ to $0.005625 \mathrm{M}$. The rate $R_{\mathrm{p}}$ remained almost constant in this range of $\left[\mathrm{Mn}^{3+}\right]$. The hydrogen ion concentration was varied from $1.5 \mathrm{M}$ to $3.5 \mathrm{M}$ at constant ionic strength. The plot of $R_{\mathrm{p}} v s . \mathrm{H}^{+}$was a straight line passing through the origin, indicating that the order with respect to $\left[\mathrm{H}^{+}\right]$was unity (Figure 1C). The effect of ionic strength on the rate of polymerization was not very significant.

Rate of $\mathrm{Mn}^{3+}$ Disappearance, $-R_{\mathrm{m}}$

It was observed that a direct proportionality exists between the rate of $\mathrm{Mn}^{3+}$ disappearance and monomer concentration. The plot of $-R_{\mathrm{m}}$ against [M] was linear and passed through the origin (Figure $2 \mathrm{~A}$ ). $-R_{\mathrm{m}}$ was also directly proportional to the $\mathrm{Mn}^{3+}$ concentration. The plot of $-R_{\mathrm{m}}$ against $\left[\mathrm{Mn}^{3+}\right]$ was linear and passed through the origin 


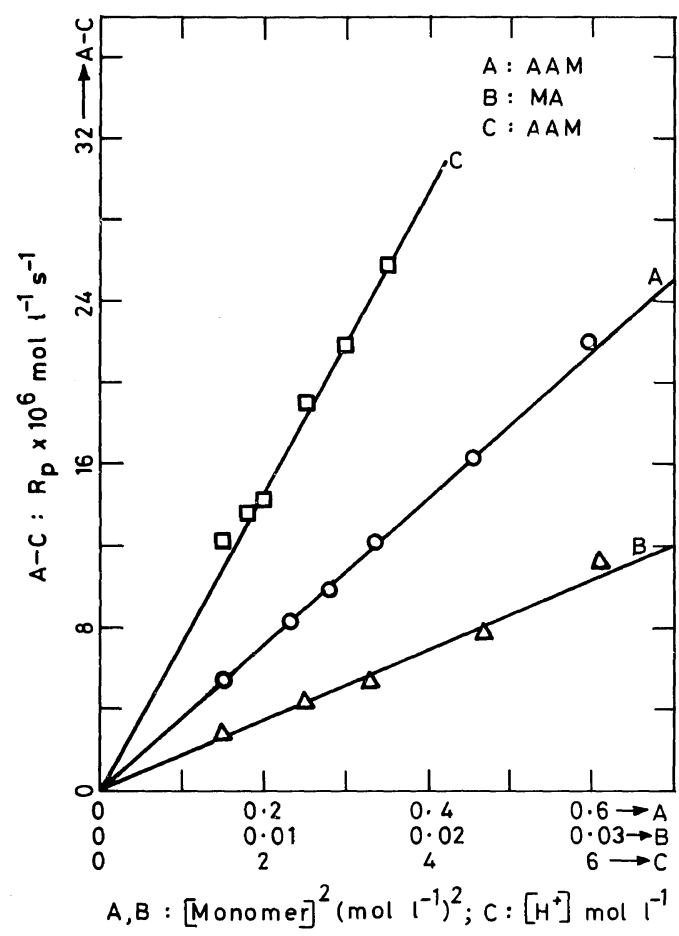

Figure 1. Polymerization of vinyl monomers (AAM and MA) by $\mathrm{Mn}^{3+}$ in aqueous sulphuric acid. (A): $R_{\mathrm{p}} v s$. $[\mathrm{AAM}]^{2}$ at constant $\left[\mathrm{Mn}^{3+}\right]=0.001962 \mathrm{M} ;\left[\mathrm{H}^{+}\right]=1.5 \mathrm{M}$; $\mu=1.9 \mathrm{M} ; T=50^{\circ} \mathrm{C}$. (B): $R_{\mathrm{p}}$ vs. $[\mathrm{MA}]^{2}$ at constant $\left[\mathrm{Mn}^{3+}\right]=0.0016 \mathrm{M} ;\left[\mathrm{H}^{+}\right]=1.0 \mathrm{M} ; \mu=1.32 \mathrm{M} ; T=45^{\circ} \mathrm{C}$. (C): $R_{\mathrm{p}}$ vs. $\left[\mathrm{H}^{+}\right]$at constant $[\mathrm{AAM}]=0.5804 \mathrm{M}$; $\left[\mathrm{Mn}^{3+}\right]=0.002005 \mathrm{M} ; \mu=3.7 \mathrm{M} ; T=50^{\circ} \mathrm{C}$.

(Figure 2C). $-R_{\mathrm{m}}$ increased with an increase in $\left[\mathrm{H}^{+}\right]$ and the plots of $-1 / R_{\mathrm{m}}$ vs. $1 /\left[\mathrm{H}^{+}\right]$were linear with an intercept on the $-1 / R_{\mathrm{m}}$ axis (Figure 3A, B). $-R_{\mathrm{m}}$ was not appreciably affected by change in ionic strength at constant hydrogen ion concentration.

Degree of Polymerization, $\bar{X}_{n}$

A direct proportionality between $\bar{X}_{n}$ and monomer concentration was observed. The plot of $\bar{X}_{n}$ against $[\mathrm{M}]$ was linear, passing through origin (Figure 4A). It was observed that an increase in $\left[\mathrm{Mn}^{3+}\right]$ lessened the degree of polymerization. A plot of $\bar{X}_{n}$ vs. $1 /\left[\mathrm{Mn}^{3+}\right]$ was linear and passed through origin (Figure 4B). $\bar{X}_{n}$ increased with an increase in $\left[\mathrm{H}^{+}\right]$and the plot of $\bar{X}_{n} v s$. $\left[\mathrm{H}^{+}\right]$was linear with an intercept on the $\bar{X}_{n}$ axis (Figure 4C). Mechanism and Rate Law

Based on the above observations, a plausible mechanism may be formulated for the polymeri- zation of acrylamide as shown below.

$\mathrm{Mn}^{3+}+\mathrm{H}_{2} \mathrm{O} \rightleftarrows \mathrm{Mn}^{3+} \mathrm{OH}^{-}+\mathrm{H}^{+}$
Initiation: $\quad \mathrm{M}+\mathrm{Mn}^{3+} \stackrel{k_{\mathrm{i}}}{\longrightarrow} \mathrm{M} \cdot+\mathrm{Mn}^{2+}+\mathrm{H}^{-}$

Propagation: $\mathbf{M} \cdot+\mathbf{M} \stackrel{k_{\mathrm{p}}}{\longrightarrow} \mathbf{M} \cdot{ }_{1}$

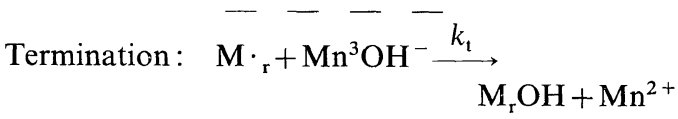

Assuming the steady state condition for the radical concentrations and also the principle of nonvariation of rate constants with the size of the polymer radical, the following expressions were derived.

$$
\begin{aligned}
& R_{\mathrm{p}}=k_{\mathrm{p}} k_{\mathrm{i}}[\mathrm{M}]^{2}\left[\mathrm{H}^{+}\right] / k_{\mathrm{t}} K \\
& -R_{\mathrm{m}}=2 k_{\mathrm{i}}\left[\mathrm{Mn}^{3+}\right]_{\mathrm{T}}\left[\mathrm{H}^{+}\right][\mathrm{M}] /\left(K+\left[\mathrm{H}^{+}\right]\right)
\end{aligned}
$$

where

$$
\begin{aligned}
& {\left[\mathrm{Mn}^{3+}\right]_{\mathrm{T}}=\left[\mathrm{Mn}^{3+}\right]+\left[\mathrm{Mn}^{3+} \mathrm{OH}^{-}\right]} \\
& \bar{X}_{n}=k_{\mathrm{p}}[\mathrm{M}]\left(K+\left[\mathrm{H}^{+}\right]\right) / k_{\mathrm{t}} K\left[\mathrm{Mn}^{3+}\right]_{\mathrm{T}}
\end{aligned}
$$

The rate of polymerization shows a square dependence on [M]. This perhaps may be the trend only when the polymer chains are terminated by $\mathrm{OH} \cdot$ or $\mathrm{Mn}^{3+}$ or $\mathrm{Mn}^{3+} \mathrm{OH}^{-}$, whereas if the chains are terminated by the mutual type (combination or disproportionation) $R_{\mathrm{p}}$ should be proportional to $[\mathrm{M}]^{3 / 2}$. So the observed dependence of $R_{\mathrm{p}}$ on monomer concentration rules out the possibility of termination by mutual type. If $\mathrm{OH} \cdot$ is the species responsible for the termination, $-R_{\mathrm{m}}$ should be independent of the monomer concentration. Since the observed trend in $-R_{\mathrm{m}}$ is contrary to this, the probability of termination by $\mathrm{OH} \cdot$ is excluded.

It was found that $R_{\mathrm{p}}$ is independent of $\left[\mathrm{Mn}^{3+}\right]$. This fact is significant since it provides strong evidence for termination by manganic ion species. The manganic species mainly present under our experimental conditions are $\mathrm{Mn}^{3+}$ and $\mathrm{Mn}^{3+} \mathrm{OH}^{-}$. Thus, the ionic species causing initiation and termination may be identified by analysis of the dependence of $R_{\mathrm{p}}$ and $-R_{\mathrm{m}}$ on $\left[\mathrm{H}^{+}\right] . R_{\mathrm{p}}$ as well as $-R_{\mathrm{m}}$ were found to increase with $\left[\mathrm{H}^{+}\right]$and this may be the trend only when $\mathrm{Mn}^{3+}$ acts as an initiating agent and $\mathrm{Mn}^{3+} \mathrm{OH}^{-}$as a terminating agent. The same trend was observed in the polymerization of acrylonitrile using $\mathrm{Ce}^{4+}$-ethylene glycol redox ini- 


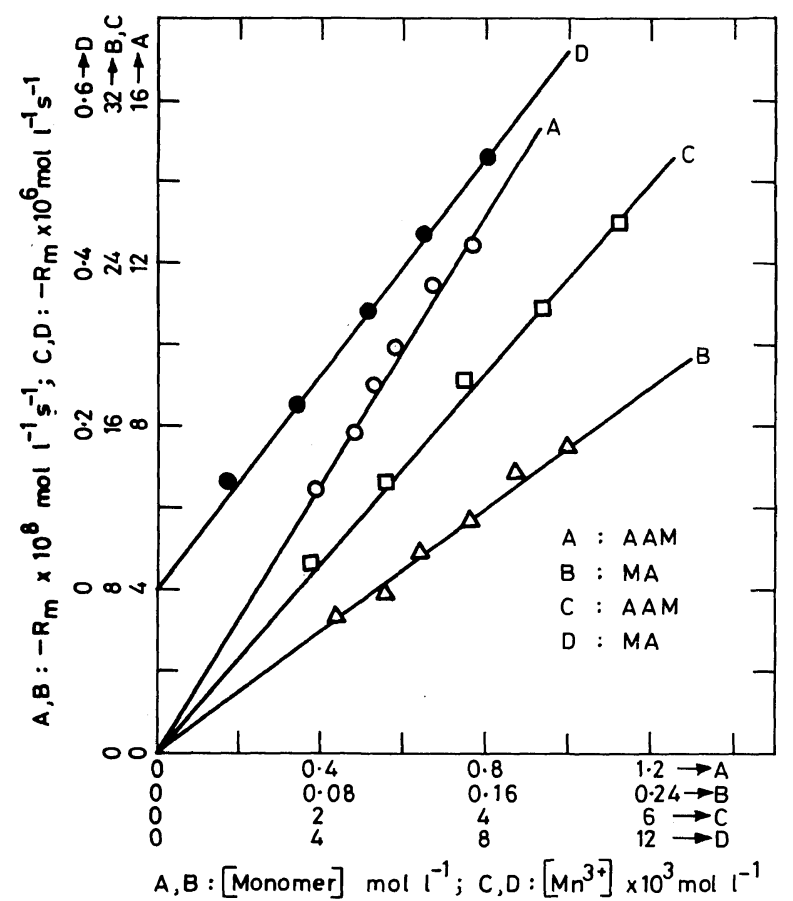

Figure 2. Polymerization of vinyl monomers (AAM and MA) by $\mathrm{Mn}^{3+}$ in aqueous sulphuric acid. (A): $-R_{\mathrm{m}} v s .[\mathrm{AAM}]^{2}$ at constant $\left[\mathrm{Mn}^{3+}\right]=0.001962 \mathrm{M} ;\left[\mathrm{H}^{+}\right]=1.5 \mathrm{M} ; \mu=1.9 \mathrm{M} ; T=50^{\circ} \mathrm{C}$. $(\mathrm{B}):-R_{\mathrm{m}} v s .[\mathrm{MA}]^{2}$ at constant $\left[\mathrm{Mn}^{3+}\right]=0.0016 \mathrm{M} ;\left[\mathrm{H}^{+}\right]=1.0 \mathrm{M} ; \mu=1.32 \mathrm{M} ; T=45^{\circ} \mathrm{C}$. $(\mathrm{C}):-R_{\mathrm{m}} v s .\left[\mathrm{Mn}^{3+}\right]$ at constant $[\mathrm{AAM}]=0.5788 \mathrm{M} ;\left[\mathrm{H}^{+}\right]=20 \mathrm{M} ; \mu=2.4 \mathrm{M} ; T=50^{\circ} \mathrm{C}$. (D): $-R_{\mathrm{m}} v s .\left[\mathrm{Mn}^{3+}\right]$ at constant $[\mathrm{MA}]=0.1370 \mathrm{M}$; $\left[\mathrm{H}^{+}\right]=1.5 \mathrm{M} ; \mu=1.9 \mathrm{M} ; T=45^{\circ} \mathrm{C}$.

tiator by Katai et al. ${ }^{15}$ and in the polymerization of methyl acrylate by ceric perchlorate by Santappa et $a l .{ }^{16}$ The trend in $R_{\mathrm{p}}$ and $-R_{\mathrm{m}}$ would be just the reverse under the conditions of initiation by $\mathrm{Mn}^{3+} \mathrm{OH}^{-}$and termination by $\mathrm{Mn}^{3+}$, as observed in the polymerization of acrylic acid, acrylontrile, methacrylic acid and methacrylamide by manganic acetate in aqueous sulphuric acid. ${ }^{9}$ Termination by metal ions has been proved beyond doubt by Dainton et al. ${ }^{17-19}$ They found that in the X-and $\gamma$-ray initiated polymerization of acrylamide in an aqueous medium, ceric ions behaved as terminating agents. The oxidative and reductive termination of poly(acrylamide) radicals by metal ions such as $\mathrm{Fe}^{3+}, \mathrm{Cu}^{2+}, \mathrm{Tl}^{3+}$, etc. were also investigated by Dainton et al. Vanadyl and Uranyl ions ${ }^{20}$ were found to terminate poly(acrylamide) radicals. Watanabe and $\mathrm{Kiuchi}^{21}$ found that cupric salts terminated poly(acrylonitrile) radicals in an aqueous solution. In the polymerization of acrylonitrile initiated by $\mathrm{V}^{5+}$-organic substrates redox sys- tems $\mathrm{s}^{22,23}$ the terminating species was $\mathrm{V}^{5+}$. The dependence of $\bar{X}_{n}$ on $[\mathrm{M}],\left[\mathrm{H}^{+}\right]$and $\left[\mathrm{Mn}^{3+}\right]^{-1}$ also confirm the reaction path involving initiation by $\mathrm{Mn}^{3+}$ and termination by $\mathrm{Mn}^{3+} \mathrm{OH}^{-}$.

\section{Evaluation of Kinetic Parameters}

The rate constant for initiation, $k_{\mathrm{i}}$ was evaluated from the intercept of the plot of $-1 / R_{\mathrm{m}}$ vs. 1/ $\left[\mathrm{H}^{+}\right]$(Figure 3A, B) which was equal to $1 /$ $\left(2 \mathrm{k}_{\mathrm{i}}[\mathrm{M}]\left[\mathrm{Mn}^{3+}\right]_{\mathrm{t}}\right)$. The slope was equal to $K /$ $\left(2 k_{\mathrm{i}}[\mathrm{M}]\left[\mathrm{Mn}^{3+}\right]\right)_{\mathrm{T}}$. Hence, the slope was divided by the intercept to obtain the value of the equilibrium constant, $K$. Substituting $k_{\mathrm{i}}$ and $K$ in the rate expression for $R_{\mathrm{p}}$, the value of $k_{\mathrm{p}} / \mathrm{k}_{\mathrm{t}}$ was obtained. The values of $k_{\mathrm{p}} / k_{\mathrm{t}}, k_{\mathrm{i}}$, and $K$ at $45^{\circ} \mathrm{C}$ were $0.4291,3.30 \times 10^{-5} 1 \mathrm{~mol}^{-1} \mathrm{~s}^{-1}$ and 0.89 $\mathrm{mol} 1^{-1}$ and at $50^{\circ} \mathrm{C}$ were $0.3137,7.81 \times 10^{-5}$ $1 \mathrm{~mol}^{-1} \mathrm{~s}^{-1}$, and $1.01 \mathrm{~mol}^{-1}$, respectively. $\Delta E$ for $k_{\mathrm{p}} k_{\mathrm{i}} / k_{\mathrm{t}} K, k_{\mathrm{p}} / k_{\mathrm{t}}$, and $k_{\mathrm{i}}$ were $17.29,-12.79$,

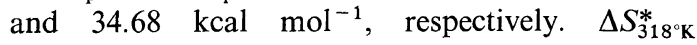
for these were $-27.61,-105.16$, and 34.47 e.u., respectively. 


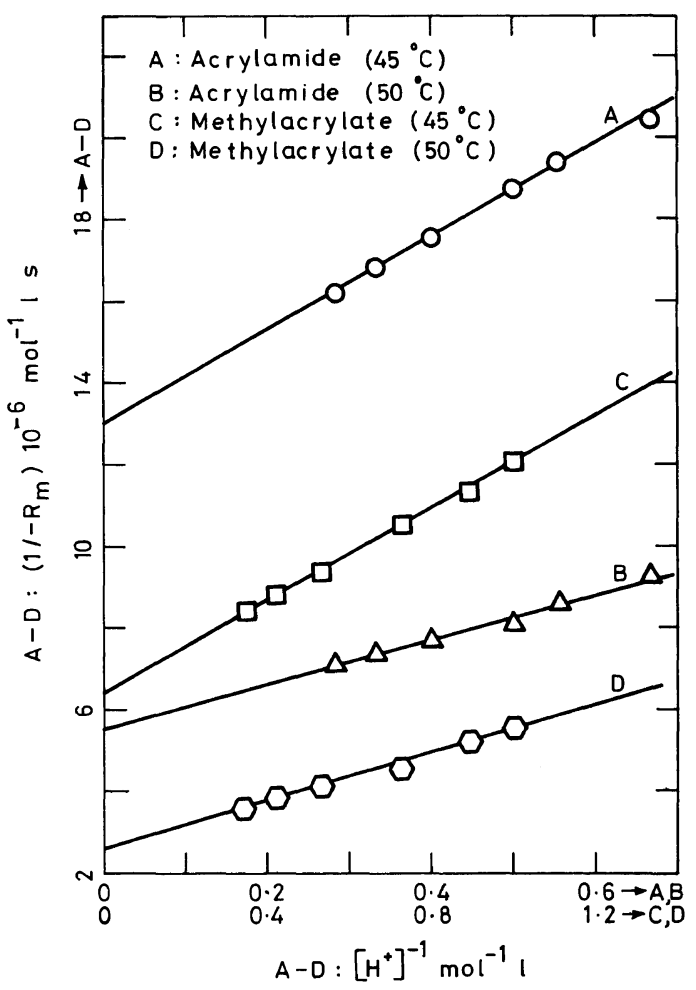

Figure 3. Polymerization of vinyl monomers (AAM and MA) by $\mathrm{Mn}^{3+}$ in an aqueous sulphuric acid. Plots of $-1 / R_{\mathrm{m}}$ vs. $\left[\mathrm{H}^{+}\right]^{-1}(\mathrm{~A})$ at constant $[\mathrm{AAM}]=0.5804 \mathrm{M}$, $\left[\mathrm{Mn}^{3+}\right]=0.002005 \mathrm{M}, \mu=3.7 \mathrm{M}, T=45^{\circ} \mathrm{C}$, (B) at constant $[\mathrm{AAM}]=0.5804 \mathrm{M},\left[\mathrm{Mn}^{3+}\right]=0.002005 \mathrm{M}, \mu=$ $3.7 \mathrm{M}, T=50^{\circ} \mathrm{C},(\mathrm{C})$ at constant $[\mathrm{MA}]=0.1054 \mathrm{M}$, $\left[\mathrm{Mn}^{3+}\right]=0.00158 \mathrm{M}, \mu=3.125 \mathrm{M}, T=45^{\circ} \mathrm{C}$, and (D) at constant $[\mathrm{MA}]=0.1054 \mathrm{M},\left[\mathrm{Mn}^{3+}\right]=0.00158 \mathrm{M}, \mu=$ $3.125 \mathrm{M}, T=50^{\circ} \mathrm{C}$.

\section{(B) $\mathrm{Mn}^{3+}-$ Methyl Acrylate-Sulphuric Acid System}

The reaction path of the polymerization of methyl acrylate is different from that of acrylamide discussed in part (A) and hence its kinetic results are separately discussed.

Rate of Disappearance of the Monomer, $R_{0}$

The monomer concentration was varied from $0.08752 \mathrm{M}$ to $0.19690 \mathrm{M}$. $R_{\mathrm{p}}$ increased with an increase in [M]. The $\log R_{\mathrm{p}} v s . \log [\mathrm{M}]$ plot yielded a slope of two and the plot of $R_{\mathrm{p}}$ against [M] ${ }^{2}$ was linear, passing through the origin indicating that the order with respect to monomer concentration was two (Figure 1C). The $\left[\mathrm{Mn}^{3+}\right]$ concentration was varied from $1.915 \times 10^{-3} \mathrm{M}$ to $8.075 \times 10^{-3} \mathrm{M}$. The

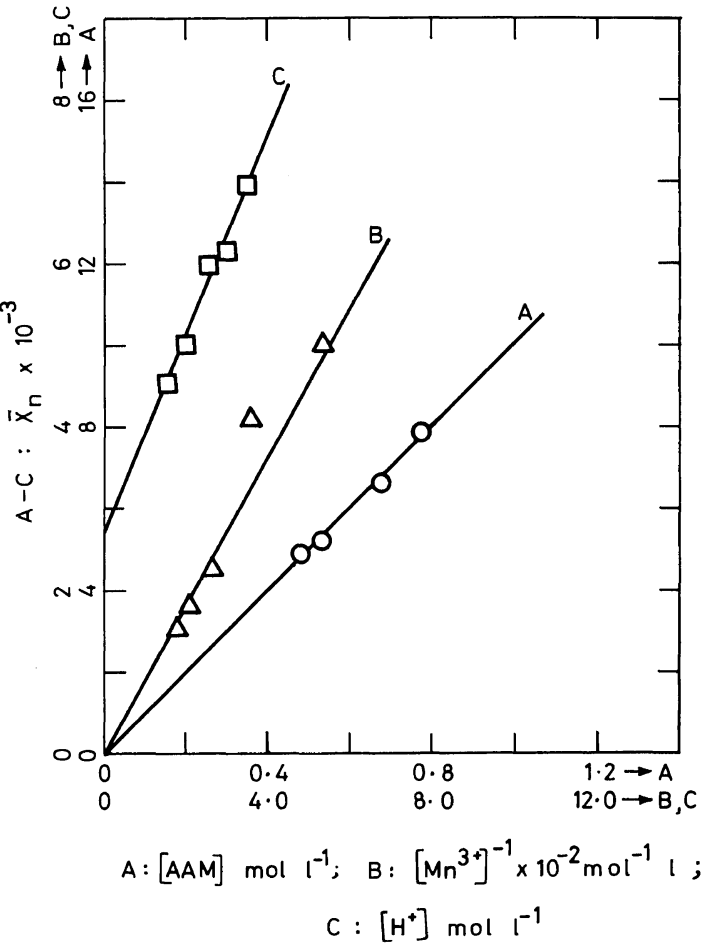

Figure 4. Polymerization of acrylamide by $\mathrm{Mn}^{3+}$ in aqueous sulphuric acid (A) $\bar{X}_{n}$ vs. [AAM], at constant $\left[\mathrm{Mn}^{3+}\right]=0.002004 \mathrm{M},\left[\mathrm{H}^{+}\right]=1.5 \mathrm{M}, \quad \mu=1.7 \mathrm{M}, \quad T=$ $45^{\circ} \mathrm{C}$, (B) $\bar{X}_{n} v s$. $\left[\mathrm{Mn}^{3+}\right]^{-1}$ at constant [AAM] $0.5788 \mathrm{M}$, $\left[\mathrm{H}^{+}\right]=1.5 \mathrm{M}, \mu=1.7 \mathrm{M}, T=45^{\circ} \mathrm{C}$, and (C) $\bar{X}_{n} v s .\left[\mathrm{H}^{+}\right]$at constant $[\mathrm{AAM}]=0.5804 \mathrm{M},\left[\mathrm{Mn}^{3+}\right]=0.002004 \mathrm{M}, \mu=$ 3.7 M, $T=45^{\circ} \mathrm{C}$.

rate of polymerization was found to decrease very slightly with $\left[\mathrm{Mn}^{3+}\right]$ and hence no definite order could be assigned with respect to $\left[\mathrm{Mn}^{3+}\right]$. The hydrogen ion concentration varied from $1.0 \mathrm{M}$ to $2.875 \mathrm{M}$ and $R_{\mathrm{p}}$ was found not appreciably influenced by a change in $\left[\mathrm{H}^{+}\right]$. The ionic strength had no significant influence on $R_{\mathrm{p}}$.

Rate of Disappearance of the Manganic Ion, $-R_{\mathrm{m}}$

A direct proportionality was found between $-R_{\mathrm{m}}$ and monomer concentration. A plot of $-R_{\mathrm{m}} v s$. [M] was linear and passed through the origin (Figure 2B). A plot of $-R_{\mathrm{m}}$ against $\left[\mathrm{Mn}^{3+}\right]_{\mathrm{T}}$ was linear passing through origin (Figure 2D) indicating that the order with respect to $\left[\mathrm{Mn}^{3+}\right]$ was unity. It was found that $-R_{\mathrm{m}}$ increased with an increase in $\left[\mathrm{H}^{+}\right]$. The plot of $-1 / R_{\mathrm{m}}$ vs. $1 /\left[\mathrm{H}^{+}\right]$was linear with an intercept on the $-1 / R_{\mathrm{m}}$ axis (Figure $3 \mathrm{C}, \mathrm{D}$ ). Variation in ionic strength had a negligible effect on 


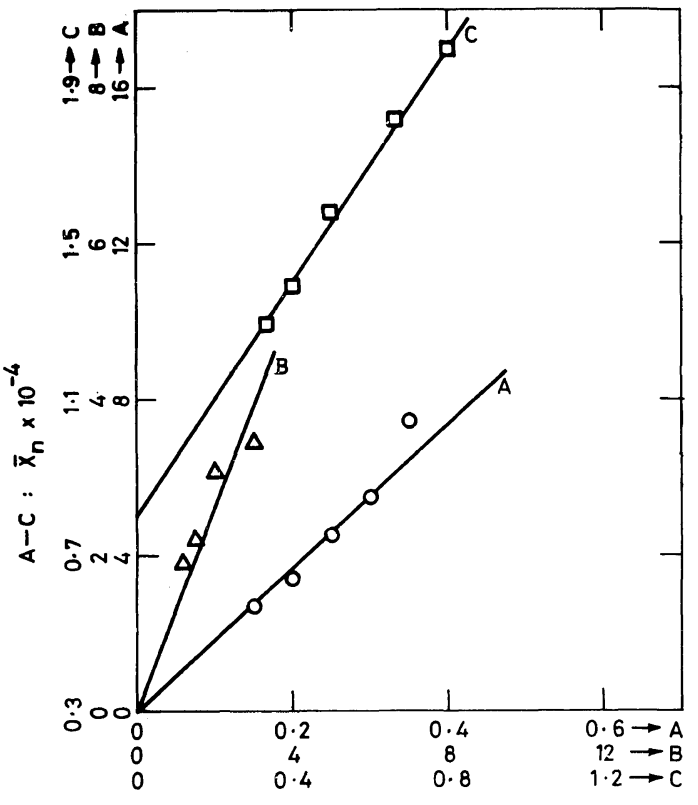

A : [MA] $\mathrm{mol} \mathrm{l} ; \quad \mathrm{B}:\left[\mathrm{Mn}^{3+}\right]^{-1} \times 10^{-2} \mathrm{~mol}^{-1} \mathrm{I}$ $C:\left[\mathrm{H}^{+}\right]^{-1} \mathrm{~mol}^{-1} \mathrm{l}$

Figure 5. Polymerization of methyl acrylate by $\mathrm{Mn}^{3+}$ in aqueous sulphuric acid (A) $\bar{X}_{n} v s$. [MA] at constant $\left[\mathrm{Mn}^{3+}\right]=0.002025 \mathrm{M},\left[\mathrm{H}^{+}\right]=1.5 \mathrm{M}, \quad \mu=1.9 \mathrm{M}, \quad T=$ $45^{\circ} \mathrm{C}$, (B) $\bar{X}_{n}$ vs. $\left[\mathrm{Mn}^{3+}\right]^{-1}$ at constant $[\mathrm{MA}]=0.2501 \mathrm{M}$, $\left[\mathrm{H}^{+}\right]=2.5 \mathrm{M}, \mu=2.9 \mathrm{M}, T=45^{\circ} \mathrm{C}$, and $(\mathrm{C}) \bar{X}_{n} v s .\left[\mathrm{H}^{+}\right]^{-1}$ at constant $[\mathrm{MA}]=0.2483 \mathrm{M},\left[\mathrm{Mn}^{3+}\right]=0.002005 \mathrm{M}, \mu=$ $3.2 \mathrm{M}, T=45^{\circ} \mathrm{C}$.

$-R_{\mathrm{m}}$

Degree of Polymrization, $\bar{X}_{n}$

The degree of polymerization of polymers obtained from methyl acrylate increased with an increase in monomer concentration. A plot of $\bar{X}_{n} v s$. $M$ was linear and passed through origin (Figure 5A). $\bar{X}_{n}$ decreased with an increase in $\left[\mathrm{Mn}^{3+}\right]_{\mathrm{T}}$ and a plot of $\bar{X}_{n}$ vs. $1 /\left[\mathrm{Mn}^{3+}\right]_{\mathrm{T}}$ gave a straight line with a zero intercept (Figure 5B). The degree of polymerization was found to decrease with increase in $\left[\mathrm{H}^{+}\right]$ and the plot of $\bar{X}_{n}$ vs. $1 /\left[\mathrm{H}^{+}\right]$was linear with an intercept on the $\bar{X}_{n}$ axis (Figure $5 \mathrm{C}$ ).

Mechanism and Rate Law

The following sequence of reactions appears to be the most probable to explain our results.

$$
\mathrm{Mn}^{3+}+\mathrm{H}_{2} \mathrm{O} \stackrel{M}{\rightleftarrows} \mathrm{Mn}^{3+} \mathrm{OH}^{-}+\mathrm{H}^{+}
$$

Initiation: $\quad \mathrm{M}+\mathrm{Mn}^{3+} \stackrel{k_{\mathrm{i}}}{\longrightarrow} \mathrm{M} \cdot+\mathrm{Mn}^{2+}+\mathrm{H}^{+}$
Propagation : $\mathbf{M} \cdot+\mathbf{M} \stackrel{k_{\mathrm{p}}}{\longrightarrow} \mathrm{M}$.

Termination : $\mathbf{M} \cdot+\mathrm{Mn}^{3}+\stackrel{k_{\mathrm{t}}}{\longrightarrow} \mathrm{M}+\mathrm{Mn}^{2+}+\mathrm{H}^{+}$

Assuming the usual stationary-state kinetics for initiation and termination by $\mathrm{Mn}^{3+}$, the following equations were derived:

$$
\begin{aligned}
& R_{\mathrm{p}}=k_{\mathrm{p}} k_{\mathrm{i}}[\mathrm{M}]^{2} / k_{\mathrm{t}} \\
& -R_{\mathrm{m}}=2 k_{\mathrm{i}}\left[\mathrm{Mn}^{3+}\right]_{\mathrm{T}}\left[\mathrm{H}^{+}\right][\mathrm{M}] /\left(K+\left[\mathrm{H}^{+}\right]\right) \\
& \bar{X}_{n}=k_{\mathrm{p}}[\mathrm{M}]\left(K+\left[\mathrm{H}^{+}\right]\right) / k_{\mathrm{t}}\left[\mathrm{Mn}^{3+}\right]_{\mathrm{T}}\left[\mathrm{H}^{+}\right]
\end{aligned}
$$

$R_{\mathrm{p}}$ is independent of $[\mathrm{H}]$ and $\left[\mathrm{Mn}^{3+}\right]$ but has a square dependence on monomer concentration. These trends in $R_{\mathrm{p}}$ can be observed only under the conditions of initiation as well as termination caused by the same ionic species of manganese. The metal ion species which can produce such results in this systems is either $\mathrm{Mn}^{3+}$ or $\mathrm{Mn}^{3+} \mathrm{OH}^{-} .-R_{\mathrm{m}}$ is linearly related to $[\mathrm{M}],\left[\mathrm{Mn}^{3+}\right]$, and $\left[\mathrm{H}^{+}\right]$. These trends in $-R_{\mathrm{m}}$ are possible only when $\mathrm{Mn}^{3+}$ acts as the initiating as well as terminating agent. If $\mathrm{Mn}^{3+} \mathrm{OH}^{-}$ionic species causes both initiation and termination, $-R_{\mathrm{m}}$ will decrease with an increase in $\left[\mathrm{H}^{+}\right]$. Since such a trend in $-R_{\mathrm{m}}$ is not observed, it may be concluded that $\mathrm{Mn}^{3+}$ is the species responsible for initiation as well as the termination of polymerization. The dependence of the degree of polymerization on $[\mathrm{M}],\left[\mathrm{H}^{+}\right]^{-1}$, and $\left[\mathrm{Mn}^{3+}\right]^{-1}$ is also in conformity with the reaction scheme proposed and rate expressions derived on the basis of initiation and termination of polymerization caused by $\mathrm{Mn}^{3+}$ ion.

\section{Evaluation of Kinetic Parameters}

The initiation rate constants $\left(k_{\mathrm{i}}\right)$ at two different temperatures were evaluated from the intercept of the plots of $1 / R_{\mathrm{m}}$ vs. $1 /\left[\mathrm{H}^{+}\right]$(Figures $3 \mathrm{C}, \mathrm{D}$ ). The intercept on the $-1 / R_{\mathrm{m}}$ axis was equal to $1 /$ $\left(2 k_{\mathrm{i}}[\mathrm{M}]\left[\mathrm{Mn}^{3+}\right]_{\mathrm{T}}\right.$ and the slope was equal to $K /$ $\left(2 k_{\mathrm{i}}[\mathrm{M}]\left[\mathrm{Mn}^{3+}\right]_{\mathrm{T}}\right)$. Hence, the slope divided by the intercept gave the equilibrium constant values $K$. Then, using the expression $k_{\mathrm{i}}=(1 /$ intercept $) \times 1 /$ $\left(2[\mathrm{M}]\left[\mathrm{Mn}^{3+}\right]_{\mathrm{T}}\right), k_{\mathrm{i}}$ was evaluated. Substituting the values of $k_{\mathrm{i}}$ in the rate expression $R_{\mathrm{p}}=k_{\mathrm{p}} k_{\mathrm{i}}[\mathrm{M}]^{2} / k_{\mathrm{t}}$ the value of $k_{\mathrm{p}} / k_{\mathrm{t}}$ was obtained for two different temperatures. The value of $k_{\mathrm{p}} / k_{\mathrm{t}}, k_{\mathrm{i}}$, and $K$ at $45^{\circ} \mathrm{C}$ were $0.7159,4.64 \times 10^{-4} 1 \mathrm{~mol}^{-1} \mathrm{~s}^{-1}$ and 0.8984 
mol $1^{-1}$ and at $50^{\circ} \mathrm{C}$ were $0.4311,1.15 \times 10^{-3}$ $1 \mathrm{~mol}^{-1} \mathrm{~s}^{-1}$ and $1.1150 \mathrm{moll}^{-1}$, respectively. $\Delta E$ for $k_{\mathrm{p}} k_{\mathrm{i}} / k_{\mathrm{t}}, k_{\mathrm{p}} / k_{\mathrm{t}}$, and $k_{\mathrm{i}}$ were $16.07,-20.70$, and 36.78 $\mathrm{kcal} \mathrm{mol}^{-1}$, respectively. $\Delta S_{318^{\circ} \mathrm{K}}^{*}$ for these were -32.97 , -124.42 , and 41.76 e.u., respectively.

Acknowledgement. One of the authors, $\mathrm{K}$. Kaliyamurthy should like to express his appreciation to the University Grants Commission, New Delhi, for the award of a Teacher Fellowship.

\section{REFERENCES}

1. C. F. Wells and D. Mays, J. Chem. Soc. Sect. A, 665 (1968).

2. P. Elayaperumal, T. Balakrishnan, and M. Santappa, Indian J. Chem., 17A, 179 (1979).

3. H. Land and W. A. Waters, J. Chem. Soc., 2129 (1958).

4. C. H. Bamford and A. N. Ferrar, Proc. R. Soc. London, Ser. A, 321, 425 (1971).

5. N. Gangadevi and V. Mahadevan, Makromol. Chem., 152, 177 (1972).

6. D. N. Ganga and V. Mahadevan, J. Polym. Sci., Polym. Lett. Ed., 10, 903 (1972).

7. N. Gangadevi and V. Mahadevan, Makromol. Chem., 166, 209 (1973)

8. P. Elayaperumal, Ph.D. Thesis, University of Madras, 1979.
9. K. Kaliyamoorthy, P. Elayaperumal, T. Balakrishnan, and M. Santappa, unpublished data.

10. F. S. Dainton and M. Tordoff, Trans. Faraday Soc., 53, 499 (1957).

11. K. Jijie, M. Santappa, and V. Mahadevan, J. Polym. Sci., 4, 393 (1966).

12. P. J. Andrulis, Jr., M. J. S. Devar, R. Dietz, and R. L. Hunt, J. Am. Chem. Soc., 88, 5473 (1966).

13. E. Collinson, F. S. Dainton, and G. S. McNaughton, Trans. Faraday Soc., 53, 489 (1957).

14. H. Matsuda, K. Yamario, and H. Inagaki, J. Polym. Sci., A-2, 7, 609 (1969).

15. A. A. Katai, V. K. Kulshrestha, and R. H. Marchessault, J. Phys. Chem., 68, 522 (1964).

16. S. Venkatakrishnan and M. Santappa, Makromol. Chem., 27, 51 (1958).

17. E. Collinson, F. S. Dainton, D. R. Smith, G. J. Trudel, and (in part) S. Tazuke, Discuss. Faraday Soc., 29, 188 (1960).

18. F. S. Dainton and D. G. L. James, Trans. Faraday Soc., 54, 649 (1958).

19. F. S. Dainton and P. H. Scaman, J. Polym. Sci., 39, 279 (1959).

20. E. A. S. Cavell and A. C. Meeks, Makromol. Chem., 78, 178 (1964); ibid., 73, 145 (1964).

21. M. Watanabe and H. Kiuchi, J. Polym. Sci., 58, 103 (1962).

22. S. Saccubai and M. Santappa, J. Polym. Sci., A-1, 7, 643 (1969).

23. S. Saccubai and M. Santappa, Proc. Indian Acad. Sci., LXXI, 111 (1970). 